Rocío González de Arce Arzave

El Padrino III a modo de Estudio de Caso

Revista Xihmai XI (21), 9-28, Enero - junio 2016

\title{
Xíhmai
}

Universidad La Salle Pachuca

xihmai@lasallep.edu.mx

Teléfono: 01(771) 7170213 ext. 1406

Fax: 01(771) 7170309

ISSN (versión impresa):1870_6703

México

2016

Rocío González de Arce Arzave

"El PADRINO III A MOdo DE Estudio DE CASO"

“The Godfather III AS A CASE STUdy"

Xihmai, año 2016/vol. XI, número 21

Universidad La Salle Pachuca

pp. $9-28$

Xihmai 9 
Rocío González de Arce Arzave

El Padrino III a modo de Estudio de Caso

Revista Xihmai XI (21), 9-28, Enero - junio 2016

Xihmai 10 
Rocío González de Arce Arzave

El Padrino III a modo de Estudio de Caso Revista Xihmai XI (21), 9-28, Enero - junio 2016

\section{El PADRINO III A MODO DE ESTUdIO DE CASO}

\section{THE GODFATHER III AS A CASE STUDY}

Rocío González de Arce Arzave Egresada de la Facultad de Ciencias de la Universidad Autónoma de México, coordinadora de Cineclub CírculoKiné y socia fundadora de la Red Enlace

Cineclubista, A. C. chioglezarce@hotmail.com

Recibido 17-02-15* Aceptado 25-05-15* Corregido 19 - 07-15

\section{Resumen}

El artículo expone la necesidad de acercar el cineclubismo al ámbito académico con el uso del análisis interpretativo de secuencias como herramienta para enriquecer y construir la sesión cineclubista. El trabajo presenta como estudio de caso el análisis textual interpretativo de la dimensión operística de las secuencias finales de El Padrino, parte III (Coppola, 1990). Se discuten ampliamente los resultados de este análisis y se utilizan para diseñar el contenido de un programa de mano que incluye fotogramas clave, información pertinente para la presentación de la película y preguntas guía para el cinedebate. El trabajo concluye que el análisis genológico, intertextual y de los componentes formales de las secuencias clave de una película permite encontrar premisas fundamentales del texto fílmico que sirven para diseñar estrategias de presentación y moderación de la sesión cineclubista, decidir el contenido de los materiales impresos que se entregan a los asistentes y armar la programación de ciclos. Se discuten las limitaciones del análisis cinematográfico como apoyo para la actividad cineclubista y se exponen algunas opciones para superar dichas limitaciones.

Palabras clave: Análisis interpretativo de secuencias, El Padrino III, dimensión operística, cinedebate, sesión cineclubista

\section{Abstract}

This article discusses the need to bring film clubbing closer to academic spheres by using interpretative sequence analysis as a tool to enrich and build the film club session. The paper presents, as a case study, the interpretive 
textual analysis of the operistic dimension in the final sequences of The Godfather, Part III (Coppola, 1990). The results of this analysis are widely discussed and then used to design the content of a hand programme that includes key frames, information relevant to the presentation of the film and guide questions to the film club debate. The paper concludes that the generic, intertextual and formal component analysis of the key sequences of a film, enables finding the main premises of the film text and using them to design presentation and moderation strategies within the film club session, planning the content of the printed materials that are handed in to the audience, and deciding the film club programme. The limitations of film analysis as a support for film club activities are discussed, and some options to overcome these limitations are offered.

Key words: interpretative sequence analysis, The Godfather III, operistic dimension, film club debate, film club session

\section{Introducción}

Hace más de cincuenta años, Manuel González Casanova (1960, p. 10) definió los cineclubes como: "verdaderos seminarios de cine encargados de educar y organizar al público". En una reciente conferencia en la Cineteca Nacional, Gabriel Rodríguez (2014) apuntó que: "el cineclub es el público, que organizado, decide lo que quiere ver". Retomar ambas ideas nos permite definir al cineclub como un espacio de educación audiovisual, organizado por el propio público.

Aunque desde mediados de los años cincuenta, el cineclubismo ha sido parte de las actividades cotidianas de escuelas y facultades de nuestro país; el cineclub, como espacio de educación audiovisual, ha permanecido por lo general lejos del ámbito académico.

Por un lado, las publicaciones al respecto de la actividad cineclubista en México son escasas, y entre ellas sólo se cuentan algunos trabajos importantes: el libro canónico de Manuel González Casanova (1960), ¿Qué es un cineclub?, el manual de José Rovirosa (1970) titulado Cine-Club, y un par de tesis (Rodríguez Álvarez, 2002 y Saavedra del Rayo, 2002)-; asimismo las publicaciones realizadas por los cineclubes (memorias, revistas, boletines, artículos) son prácticamente inexistentes y se concentran en la difusión o la crítica cinematográfica.

Xihmai 12 
Por otra parte, la presentación de la película y el debate cineclubista posterior a la proyección, se centran en la mayoría de los casos, en el contexto y en el tema del filme, y dejan de lado la discusión de lo formal.

Desde la perspectiva de las tradiciones formalistas, sin embargo, es imposible separar la forma de una obra, de su contenido, pues la forma es el contenido mismo (Zavala, 2010a). A partir de este principio, se vuelve necesario reconocer que para que un cineclub funcione como un verdadero espacio de educación audiovisual para sus miembros, resulta indispensable que se eche mano del análisis cinematográfico.

Pero, ¿de qué manera es posible utilizar el análisis cinematográfico para enriquecer el cineclub como espacio de educación audiovisual?

Si bien es cierto que el aprendizaje que se da durante la sesión cineclubista es en gran medida resultado del proceso de conducción narrativa al que Wayne Booth (2005 en Zavala, 2014a, p. 29) se refiere como "el proceso de compartir con otros espectadores la experiencia estética de ver una película", proponemos que el análisis interpretativo ${ }^{1}$ de secuencias pueda ser una herramienta útil para estructurar y enriquecer la sesión cineclubista, y que pueda incluso constituirse en una guía para definir la programación de ciclos. Ello porque el análisis de los componentes formales, el de la genología ${ }^{2}$ y el de la intertextualidad ${ }^{3}$ de las secuencias clave de una película, permiten encontrar las premisas fundamentales del texto fílmico, e identificar dichas premisas posibilita el diseño de estrategias de presentación de la película y de moderación del cinedebate, guía la selección de contenido de materiales impresos como programas de mano y trípticos y, en general, enriquece el visionado de los asistentes al ofrecerles otras lecturas de la película.

\footnotetext{
${ }^{1}$ De acuerdo con lo propuesto por Zavala (2010b p. 65): "el análisis interpretativo utiliza diversos métodos derivados de la teoría del cine, y tiene como objetivo precisar la naturaleza estética y semiótica de la película, para lo cual desde esta perspectiva se estudian los componentes formales de la película." Esto es: imagen, sonido, puesta en escena, narración y montaje.

${ }^{2}$ Zavala (2010c) señala que el análisis genológico deriva de la teoría de géneros narrativos y estudia las convenciones genéricas del filme.

${ }^{3}$ Para Zavala (2014b) "el concepto de intertextualidad presupone que todo texto está relacionado con otros textos, como producto de una red de significación". A esa red le llama intertexto y a su estudio análisis intertextual.
} 
El objetivo de este trabajo es corroborar esta hipótesis, para ello se presenta como estudio de caso el análisis de las secuencias finales de El Padrino, parte III (Coppola, 1990), ${ }^{4}$ mientras se utilizan los resultados de dicho análisis como guía para presentar y moderar una sesión cineclubista, y elaborar un programa de mano.

La primera sección de este artículo corresponde al Estudio de caso: análisis de las secuencias finales de El Padrino, parte III. En dicha sección se apunta la hipótesis del análisis, se refieren las investigaciones que se han realizado sobre la trilogía de El Padrino, se presenta la justificación del análisis y la sinopsis de las secuencias analizadas, se explica la metodología seguida en el análisis y se presentan los resultados del análisis formal, componente por componente (imagen, sonido, puesta en escena, montaje y narración), y del análisis genológico e intertextual. Finalmente, se discuten los resultados respecto a la hipótesis planteada.

Una segunda sección, El análisis como guía para la sesión cineclubista, presenta la manera en que los resultados obtenidos en el análisis de secuencias permiten diseñar el contenido del programa de mano de la sesión cineclubista en términos de la presentación de la película y de las preguntas que guían el cinedebate.

La última sección corresponde a las conclusiones generales del artículo respecto a las posibilidades del análisis cinematográfico como herramienta para la construcción de la sesión cineclubista.

Estudio de caso: análisis de las secuencias finales de El Padrino, parte III Hipótesis y antecedentes. El análisis de las secuencias finales de El Padrino, Parte III busca poner a prueba la hipótesis que contiene una de las premisas de la película, la cual sostiene que la historia familiar de Los Corleone es una

\footnotetext{
${ }^{4}$ Ficha técnica: The Godfather. Part III. Estados Unidos, 1990, 162 min. D: Francis Ford Coppola; G: Mario Puzo, Francis Ford Coppola; F en C: Gordon Willis; M: Carmine Coppola; E: Lisa Fruchtman, Barry Malkin y Walter Murch; Con: Al Pacino, Diane Keaton, Andy García, Joe Mantegna, George Hamilton, Talia Shire, Sofia Coppola, Eli Wallach, Don Novello, Bridget Fonda, John Savage, Al Martino, Raf Vallone, Franc D'ambrosio, Donal Donnelly, Richard Bright, Helmut Berger. Sinopsis: Michael Corleone, heredero del imperio de su padre, intenta redimirse y legitimar todos los negocios sucios de la familia infructuosamente. Michael centra entonces, todas sus esperanzas en encontrar un sucesor. Vincent, hijo ilegítimo de su hermano Sonny, parece ser el elegido.
}

Xihmai 14 
ópera siciliana de venganza, amores frustrados y muerte que lleva generaciones representándose y cuyo final trágico es inevitable.

Diversos autores han hecho referencia a la relación entre la ópera y la trilogía de El Padrino. Citron (2005) apunta el estilo y estructura operática de $E l$ Padrino, Parte III; Arocena (2002, p. 237) considera la ópera como "la raíz a partir de la que nacen las sensibilidades de El Padrino" y Mackenzie (1998) y Tranrisever (2001) hacen referencia a lo operístico del montaje y la narrativa de la saga, respectivamente.

Justificación y sinopsis de las secuencias. Ninguna de las investigaciones antes mencionadas apoya sus conclusiones en el análisis de secuencias específicas, por lo que el presente trabajo propone poner a prueba la hipótesis de la dimensión operística de El Padrino, parte III a través del análisis de las secuencias de los cinco minutos finales de la película: tras haber asistido al debut de Anthony, el hijo de Michael y Kay, en la ópera Cavalleria Rusticana, la familia Corleone sale del teatro Massimo de Palermo en Sicilia. Mary, la hija de Michael, confronta a su padre para reclamarle que haya obligado a su primo Vincent a romper sus relaciones con ella para poder convertirse en el nuevo jefe de la familia. Un asesino a sueldo, Mosca, dispara sobre Michael, pero la que resulta herida es Mary, que muere en las escalinatas del teatro. Michael, en Sicilia, recuerda a las mujeres importantes de su vida y muere solo.

Metodología. Se seleccionaron las secuencias de los últimos cinco minutos de El Padrino, parte III por tratarse del cierre narrativo, no solo de la tercera parte de la saga, sino de toda la trilogía de El Padrino; se condensan elementos que permiten poner a prueba la hipótesis planteada.

Para llevar a cabo el análisis, se elaboró un decoupage $e^{5}$ de los 62 planos contenidos en las secuencias finales de El Padrino, parte III. El decoupage incluyó un total de nueve categorías por cada plano: número de plano, encuadre, movimiento de cámara, acción, música, diálogos, sonido incidental, transiciones y duración. El decoupage correspondió a lo que Vanoye y Goliot-

\footnotetext{
${ }^{5}$ Zavala (2012 p. 12) define el decoupage como un "registro preciso de los planos y la banda sonora de una secuencia o una película completa, como paso previo a la interpretación textual de un filme."
} 
Lété (2008) describen como la primera fase de un análisis cinematográfico: el desmontaje del filme o secuencia.

Una vez que las secuencias fueron desmontadas, se elaboró una hipótesis para el análisis. La hipótesis se utilizó para llevar a cabo la segunda fase del análisis que para Vanoye y Goliot-Lété (2008) consiste en establecer vínculos entre los elementos aislados de una película o secuencia, y entender cómo se asocian para permitir que aparezca un todo significante.

Los resultados del análisis se utilizaron como guía para diseñar el contenido del programa de mano de una sesión cineclubista. En dicho programa se incluyó información pertinente para la presentación de la película y una serie de preguntas conductoras del cinedebate posterior a la proyección.

Resultados del análisis de secuencias. Del análisis de la imagen destaca la alternancia de dos tipos de composición a lo largo de las secuencias analizadas. Por un lado, la mayor parte de los planos tiene una composición no central que se ajusta a la regla de tercios (Figura 1a), pero los grandes planos generales que se intercalan con los planos más cerrados presentan una composición central con un punto de fuga que dirige la mirada a la acción principal que ocurre al centro y arriba en las escalinata (Figura 1b). La composición central de los grandes planos generales enfatiza la dimensión teatral de la secuencia, mientras que los planos más cerrados permiten seguir la acción dramática.

Figura 1. Dos tipos de composición en la secuencia final de El Padrino, parte III. a) Composición no central que se ajusta a la regla de tercios y b) gran plano general que presenta una composición central con punto de fuga que dirige la mirada al centro. Fuente: fotogramas de El Padrino, parte III.
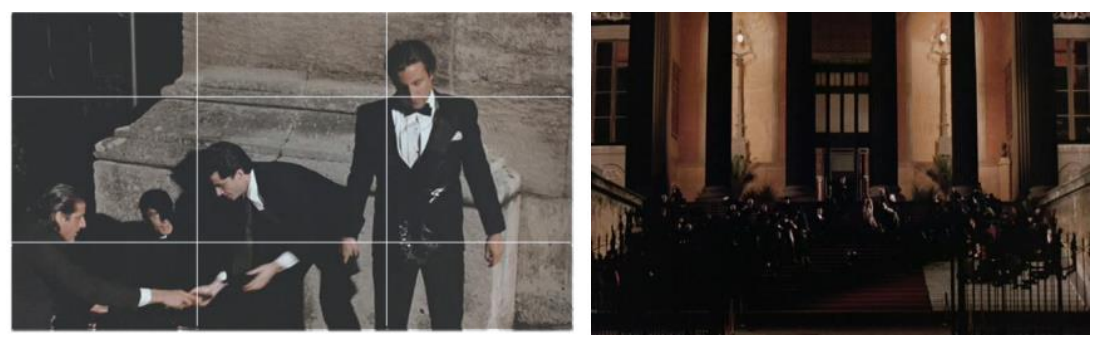

Por otra parte, si como plantea Kydd (2011): entre más cerrado es un plano, mayor es la intensidad dramática. Es posible graficar la intensidad dramática de las secuencias finales de El Padrino, parte III, así como asignarles valores Xihmai 16 
que aumenten conforme se cierra el plano al ir desde un valor de uno para el plano más abierto, es decir el gran plano general, hasta un valor de siete para el plano más cerrado, esto es el plano detalle (Figura 2).

Como se muestra en la Figura 2, los picos de intensidad dramática corresponden al tiroteo, a la muerte de Mary, al grito de Michael y al recuerdo de las mujeres de su vida; mientras que los valles corresponden a grandes planos generales de las escalinatas del Teatro Massimo de Palermo, que se intercalan con la acción y cumplen la función de ubicar al espectador en la posición de quien está viendo la representación de una ópera: la ópera de la familia Corleone.

Figura 2. Intensidad dramática por planos de las secuencias finales de El Padrino, parte III.

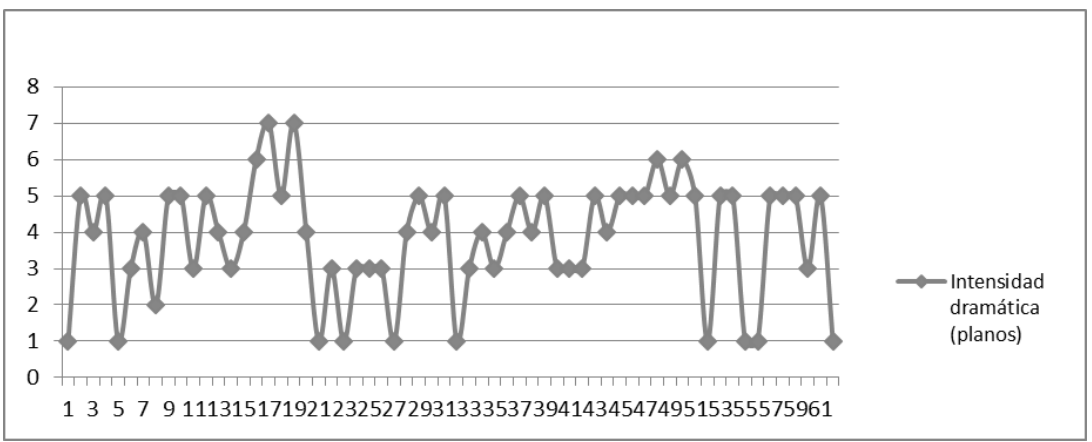

Los grandes planos generales muestran las escalinatas del teatro como el escenario de esta ópera, y la distribución de los actores en ellas refuerza esta idea. Por un lado, los personajes protagónicos (Michael y Mary) se encuentran en la parte central y superior de las escalinatas, mientras que el resto de los actores se distribuye a ambos lados de los personajes centrales de forma escalonada, a manera de los "coros" de una ópera (Figura 1b).

El vestuario también subraya la dimensión operística, pues en la escalinata se entremezclan los actores de la Cavalleria Rusticana aún con sus atuendos, los asistentes al espectáculo vestidos de gala y los sacerdotes con sotana. Destacan, de acuerdo con los comentarios del Dr. Roberto Domínguez (2014) a este trabajo, el vestido dorado de Mary que hace referencia a la figura de la doncella, el collar de perlas de Kay que la distingue como la figura materna y el velo y vestido negro de Connie que la muestran como una viuda. 
Es interesante notar el uso del silencio incidental para acentuar el clímax dramático, pues en el momento que Michael se da cuenta que su hija ha sido herida, dejan de oírse pisadas y voces, y solo se escucha a Mary decir: "Dad", en un completo vacío sonoro. Una vez que Mary cae muerta, el silencio dramático es roto por los gritos de Kay y otras mujeres, que por momentos asemejan cantos operísticos de lamento.

Paradójicamente, es el grito mudo de Michael el de mayor fuerza dramática. La imagen muestra a un Michael Corleone teñido en sangre y sentado en las escalinatas, con el rojo (¿sangre?) de la alfombra de fondo. Lo vemos gritar, pero su grito es literalmente una ópera: el intermezzo de la Cavalleria Rusticana. Su grito tarda en llegar y hacerse audible y cuando lo hace parece el aria final de una ópera.

Otros elementos permiten relacionar las secuencias finales de El Padrino, parte III, con la ópera, específicamente con la Cavalleria Rusticana. La representación que se hace de esta ópera en la película culmina con el grito: "Hanno ammazzato compare Turiddu!" (Han matado al compadre Turiddu), que anuncia la muerte del protagonista (interpretado por el propio hijo de Michael). Durante la secuencia de la muerte de Mary en las escalinatas del teatro, se escucha a una mujer fuera de cuadro gritar: "Hanno ammazzato Maria!", y "Hanno ammazzato signorina Maria!", lo que establece un claro paralelismo entre la Cavalleria Rusticana y la historia trágica de Los Corleone. Tras la muerte de Mary en las escalinatas, Connie se cubre la cabeza con un velo negro en señal de luto (Figura 3a). Ese gesto ha sido mostrado en una secuencia anterior de la película, cuando durante la representación de la Cavalleria Rusticana en el teatro, el personaje de Santuzza (Figura 3b) se cubre del mismo modo con un paño negro al saber que Turiddu ha muerto. De esta manera, la secuencia de las escalinatas pareciera la continuación de la ópera que se ha representado al interior del teatro.

Xihmai 18 
Figura 3. Los personajes femeninos cubren su cabeza con un velo negro en señal de luto. b) Santuzza en la Cavalleria Rusticana tras la muerte de Turiddu. a) Connie tras la muerte de Mary a la salida de la ópera. Fuente: fotogramas de El Padrino, parte III.
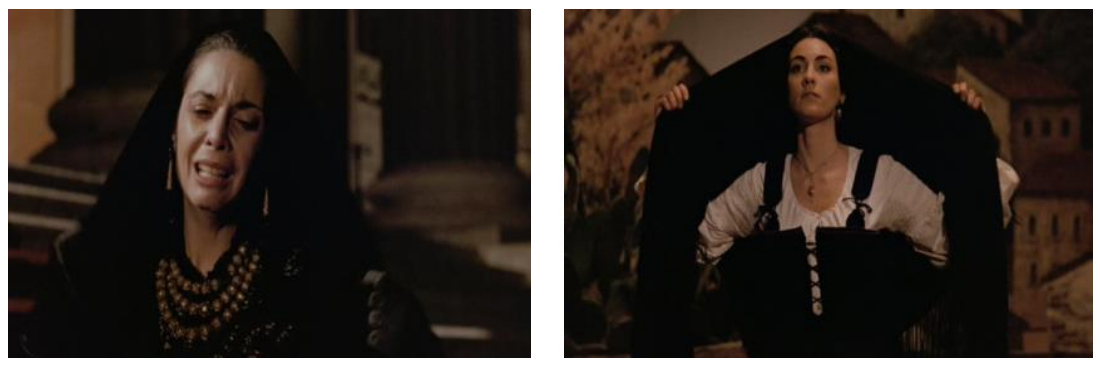

Otro momento sonoro interesante es el tintineo que se escucha sobre el Intermezzo de la Cavalleria Rusticana durante la secuencia en que Michael recuerda a las tres mujeres de su vida: su hija Mary, su primera esposa Apollonia, y su segunda esposa Kay. El tintineo se escucha mientras Michael baila con las tres mujeres (en un montaje con raccord de continuidad que las presenta como si fueran una sola, Figura 4) y es una referencia a una secuencia previa de la película en la que Michael baila con su hija mientras la gente que los rodea hace tintinear sus copas y les desea "cent'anni!", cien años de felicidad. El tintineo que se inserta extradiegéticamente en la secuencia en que Michael recuerda a las mujeres de su vida resulta pues, un comentario irónico sobre la promesa de felicidad que hizo a cada una de ellas y que fue incapaz de cumplir y refuerza además la idea tratarse de una puesta en escena.

Figura 4. Montaje con raccord de continuidad que presenta a las tres mujeres de la vida de Michael Corleone como una sola promesa de felicidad incumplida. Fuente: fotogramas de El Padrino, parte III.

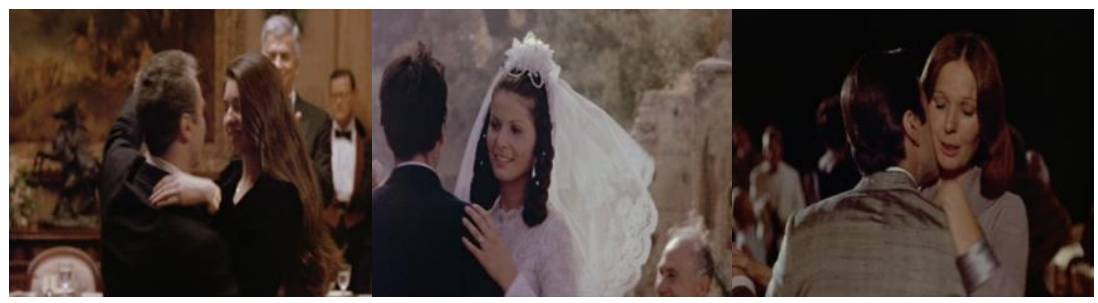

Los claroscuros y las luces cálidas cumplen una función dramática en la secuencia de las escalinatas, pues resaltan los colores utilizados en la puesta en 
escena, negros y pardos, sobre los que destacan el vestido dorado de Mary y los rojos de la alfombra de las escalinatas del teatro que varían su tonalidad, desde un rojo opaco al inicio de la secuencia, hasta un rojo sangre que se vuelve el fondo de la trágica muerte de Mary (Figura 5).

Como parte del análisis del montaje, se graficó la duración de cada plano utilizando el software CineMetrics (Tsivian y Civjans, 2005). Los resultados se pueden observar en la Figura 6. Los bloques grises y blancos representa la duración de cada plano. Los planos de menor duración son los del tiroteo en las escalinatas. La brevedad de estos planos confiere al tiroteo un ritmo rápido de montaje que acentúa la acción. Los planos más largos, por otra parte, son los que enmarcan el flashback en que el Michael recuerda a las mujeres de su vida. En general, y como lo muestra la línea roja en la gráfica de la Figura 6, el montaje de las secuencias finales de El Padrino, parte III presenta un ritmo con una tendencia general descendente que corresponde al cierre narrativo.

Figura 5. Variación tonal del rojo de las escalinatas del Teatro Massimo de Palermo, de rojo opaco al principio de la secuencia, al rojo sangre cuando se alcanza el clímax dramático. Fuente: fotogramas de El Padrino, parte III.
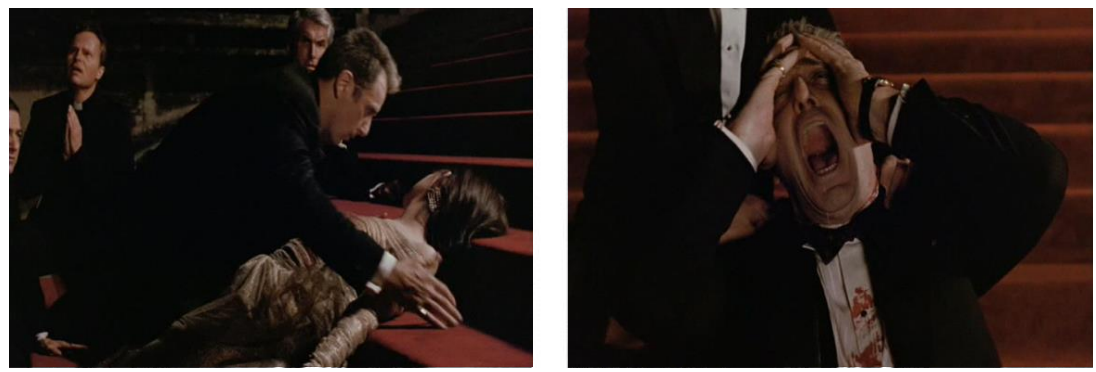

Xihmai 20 
Figura 6. Duración de los 62 planos de las secuencias finales de El Padrino, parte III. La línea roja indica la tendencia descendente del ritmo de montaje. Fotogramas de El Padrino, parte III.

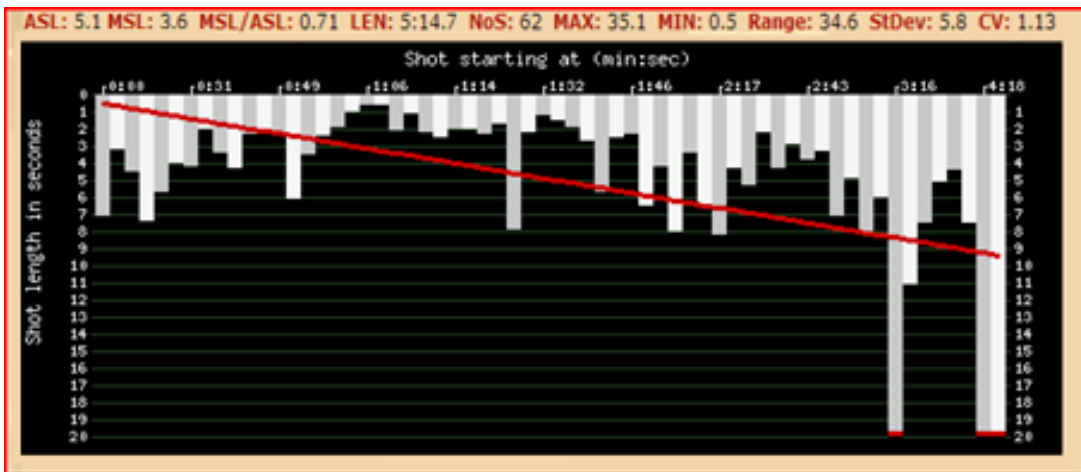

\section{SIMBOLOGÍA}

ASL: duración promedio del plano

MSL: duración media del plano

LEN: Duración de la secuencia

NoS: número de planos

MAX: Duración del plano más largo

MIN: Duración del plano más corto

RANGE: diferencia entre MIN y MAX

StDEv: Desviación estándar.

CV: Coeficiente de Variación

Por otra parte, los planos finales de la muerte de Michael, aluden a la secuencia de la muerte de Vito Corleone en la primera parte de la saga, lo que acentúa la circularidad del relato y revela una estructura especular entre la primera parte y la tercera de la trilogía.

Es de notar, sin embargo, el contraste entre la muerte de Michael y Vito Corleone. Durante sus últimos momentos Vito está rodeado de abundancia (frutos, vino) y una tierra fértil en la que el color que predomina es el verde (Figura 7a). La secuencia de la muerte de Michael en El Padrino III, lo muestra en una tierra árida con escasa vegetación, en planos en los que lo que predomina es el color de la tierra y la luz ocre (Figura 7b). Vito ha encontrado la bonanza en Norte América, Michael ha encontrado en Sicilia la derrota, el final, que es el regreso al origen; es trágico. 
Si bien la trilogía de El Padrino hunde sus raíces en el cine de gánsteres que "como antecedente del film noir, retoma elementos provenientes del expresionismo alemán y del realismo" (Zavala, 2002, P. 2-3), es también un melodrama familiar, y como tal tiene sus orígenes en la ópera italiana y sus temas de degradación moral y reivindicación a través de la muerte (comentarios personales del Dr. Roberto Domínguez, 2014).

Figura 7. Comparativa de fotogramas de la muerte de a) Vito Corleone en El Padrino I y de b) Michael en El Padrino III. Fuente: fotogramas de El Padrino, parte I y parte III.
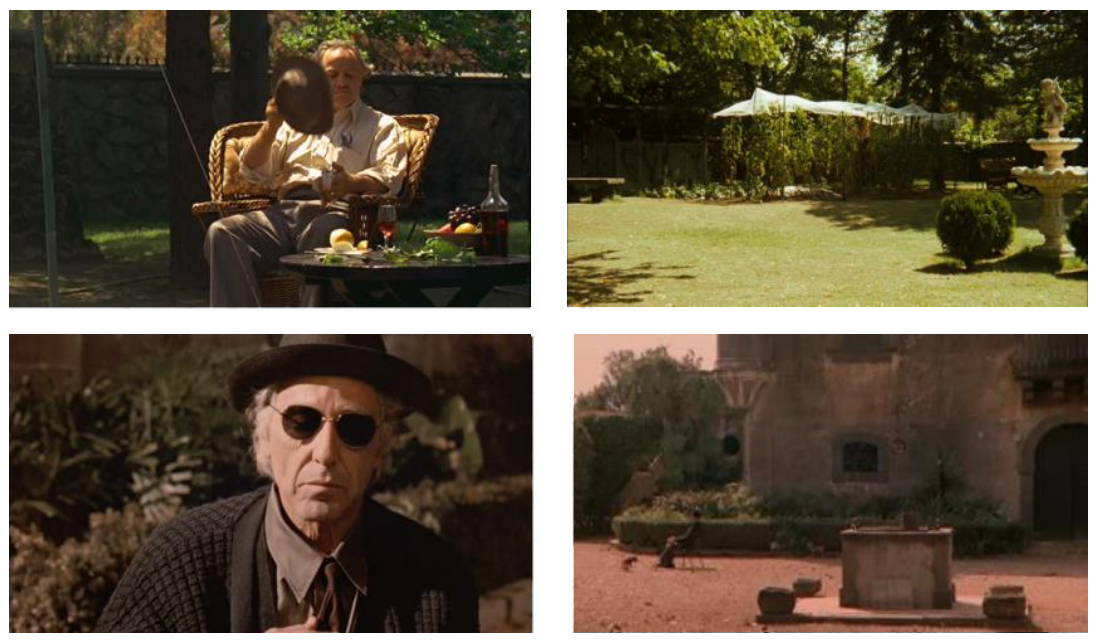

Muchas otras son las relaciones intertextuales entre el padrino y la ópera. Mosca, el nombre del asesino contratado para matar a Michael, corresponde al apellido de dos famosos compositores italianos de ópera, Luigi y Giuseppe Mosca. La novia de Anthony se llama Lola, como uno de los personajes de la Cavalleria Rusticana y la muerte de Mary hace referencia a la historia de La Baronesa di Carini, cuya tragedia fue hecha ópera por Giuseppe Mulè.

De hecho, en secuencias anteriores a las aquí analizadas, Michael y Kay recorren Sicilia y presencian una versión en teatro guiñol de la historia de la Baronesa de Carini a la que su propio padre asesina cuando descubre que está enamorada de su primo. Los paralelismo compositivos y de puesta en escena entre la representación en teatro guiñol de La Baronesa di Carini (Figura 8a) y la secuencia de la muerte de Mary (Figura 8 b) reafirman que lo que vemos Xihmai 22 
es una tragedia digna de una ópera, pues Mary, como la baronesa, muere por estar enamorada de su primo y rebelarse a la voluntad de su padre.

Figura 8. Representación de la a) Baronesa di Carini y b) la secuencia de la muerte de Mary. Fuente: fotogramas de El Padrino, parte III
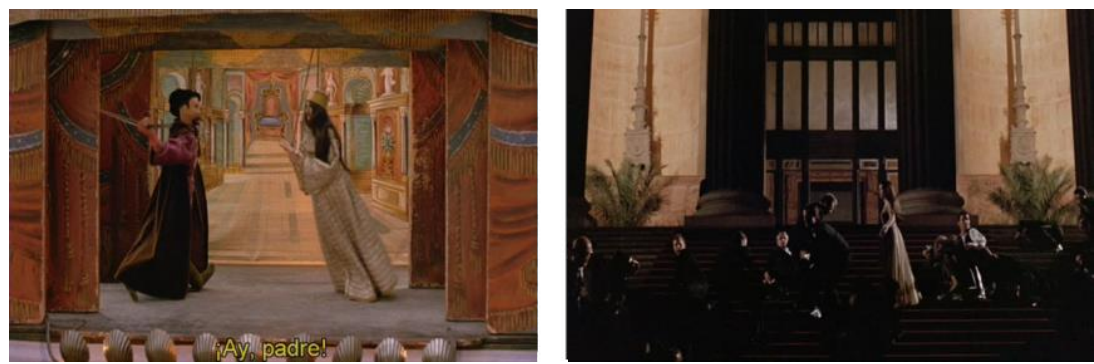

Pero sin duda es el propio Michael quien mejor resume el sentido profundo de la película cuando le plantea a Kay: "estamos en Sicilia. Esto es ópera” (Figura 9).

El análisis como guía para la sesión cineclubista

El análisis de las secuencias clave de El Padrino, parte III permitió detectar una de las premisas fundamentales del film: que la historia familiar de Los Corleone es una ópera siciliana de venganza, amores frustrados y muerte, que lleva generaciones representándose, y cuyo final trágico es inevitable.

En la dinámica de un cineclub, conocer esta premisa es de gran utilidad, pues puede: a) permitir al comité editorial del cineclub armar un ciclo de películas en el que la ópera sea un elemento fundamental; b) dar elementos al presentador de la película para formular a los asistentes preguntas que les permitan ir buscando durante el visionado de la película la relación entre cine y ópera; c) posibilitar una adecuada selección de la información que se ofrece al espectador durante la presentación del film, de manera que esta información pueda utilizarse durante el cinedebate; d) ser una guía para escoger la información y los fotogramas pertinentes para el programa de mano impreso; e) contribuir a la elaboración de preguntas que sirvan al moderador como hilo conductor del cinedebate posterior a la proyección; y f) guiar la selección de fotogramas clave para la elaboración de una presentación de diapositivas que sirva como apoyo durante el cinedebate. 
Rocío González de Arce Arzave

El Padrino III a modo de Estudio de Caso Revista Xihmai XI (21), 9-28, Enero - junio 2016

Presentamos como ejemplo de lo anterior las dos caras del tríptico del programa de mano para la sesión cineclubista en que se proyecta El Padrino, parte III. El contenido de dicho programa se diseñó con base en los resultados del análisis aquí presentado (Figura 9).

Figura 9. Tríptico del programa de mano para una sesión cineclubista, diseñado con base en los resultados del análisis de las secuencias finales de El Padrino, parte III.
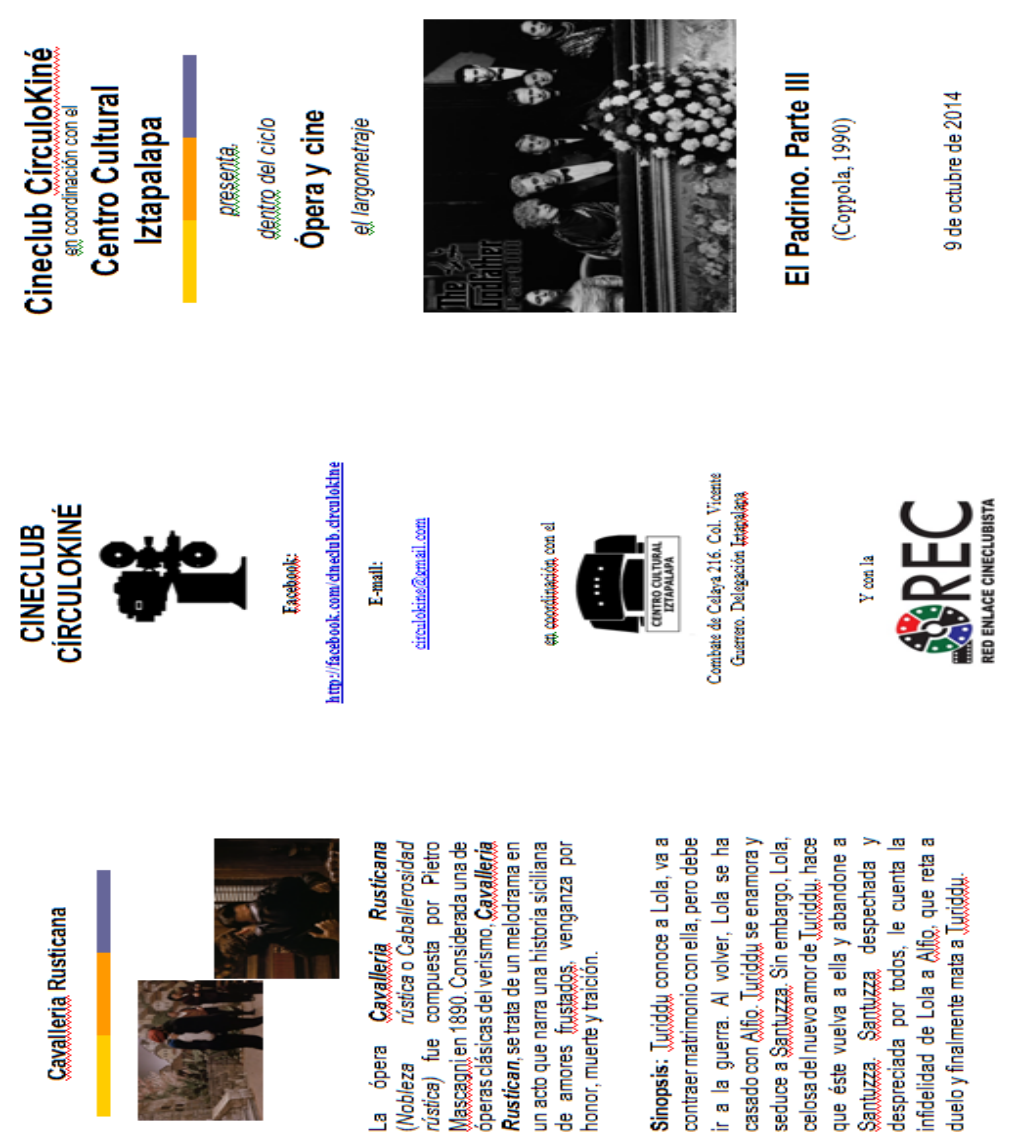

Xihmai 24 
Rocío González de Arce Arzave

El Padrino III a modo de Estudio de Caso

Revista Xihmai XI (21), 9-28, Enero - junio 2016
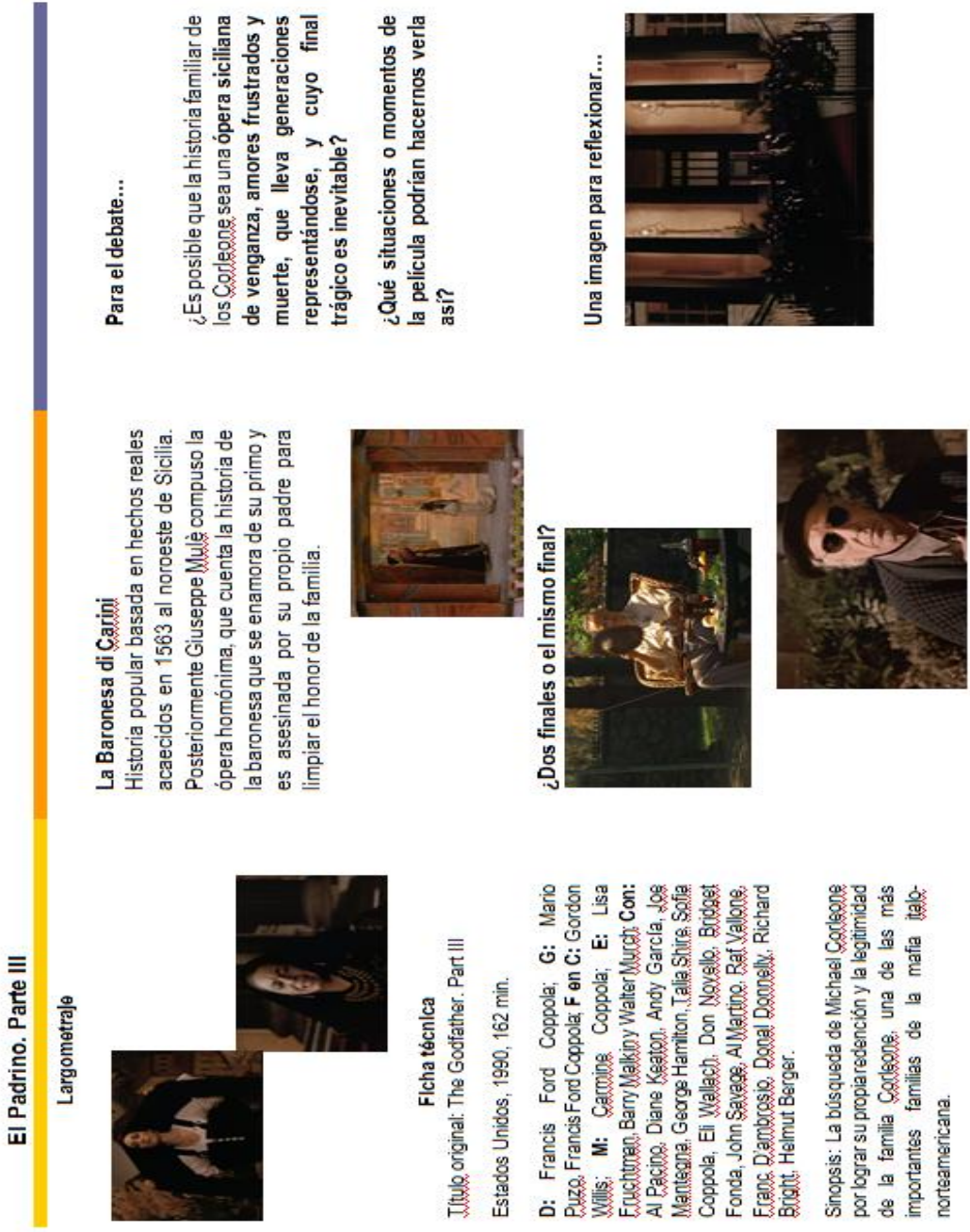
Como se observa en la Figura 9, el programa de mano incluye: fotogramas clave a los que se puede recurrir durante el cinedebate, información sobre dos óperas con las que El Padrino, parte III tiene una relación intertextual, y una serie de preguntas que pueden funcionar como el hilo conductor del debate posterior a la proyección.

\section{Conclusiones}

A manera de conclusión podemos decir que, para que un cineclub resulte un verdadero espacio de educación audiovisual, se hace indispensable vincularlo con el ámbito académico al recurrir a las herramientas que proporciona el análisis cinematográfico.

Como lo demuestra el estudio de caso presentado en este trabajo, el análisis textual, genológico e intertextual de secuencias ofrece a los organizadores de un cineclub, elementos para armar ciclos a partir de criterios que incluyan los componentes formales del cine. Asimismo, posibilita el diseño de estrategias de presentación de la película y de moderación del cinedebate, guía el diseño del contenido de materiales impresos como programas de mano y, en general, enriquece el visionado de los asistentes, ofreciéndoles otras lecturas de la película.

Para que el análisis cinematográfico sirva como herramienta para la sesión cineclubista, es necesario que los organizadores de cineclubes posean alguna preparación en materia de análisis cinematográfico y que las actividades cineclubistas se diseñen considerando los trabajos de análisis publicados en revistas o libros especializados. Ello plantea limitaciones a nuestra propuesta, pero consideramos que estas limitaciones no son insalvables, pues la gran cantidad de publicaciones especializadas, disponibles en formato impreso o electrónico, y la vasta oferta de cursos, diplomados y talleres sobre cine podrían permitir la formación académica de los organizadores cineclubistas.

Por otra parte, lo que resulta indispensable es que los analistas cinematográficos volteen la mirada al cineclub y comiencen a considerarlo un espacio de oportunidad para el desarrollo de su actividad profesional. No existen publicaciones de análisis cinematográficos en forma de guías didácticas para conducir la sesión cineclubista. Publicaciones de este tipo serían de gran apoyo para los que participan en la organización de un cineclub. Se trata de un campo aún inexplorado por los analistas de cine.

Xihmai 26 
Rocío González de Arce Arzave

El Padrino III a modo de Estudio de Caso Revista Xihmai XI (21), 9-28, Enero - junio 2016

\section{Fuentes de CONSUlta}

- AROCENA, C. (2002). Francis Ford Coppola. La trilogía de "El Padrino", España: Paidós.

- CITRON, M. J. (2005). Operatic Style and Structure in Coppola's Godfather Trilogy. The Musical Quarterly, 87:423-467.

- GONZÁLEZ CASANOVA, M. (1960). ¿Qué es un cineclub?, México: UNAM.

- KYDD, E. (2011). The Critical Practice of Film. An Introduction, Estado Unidos: Palgrave Macmillan.

- MACKENZIE, S. (1998). Closing Arias: Operatic Montage in the Closing Sequences of the Trilogies of Coppola and Leone'. Danish Journal of Film Studies, 6:109-124.

- RODRÍGUEZ ÁlvaREZ, C. G. (2002). Contemporáneos y el cineclub mexicano: revistas y cine clubes; la experiencia mexicana. Tesis de licenciatura. México: Facultad de Ciencias Políticas y Sociales, UNAM.

- ROVIROSA, J. (1970). Cine-Club, México: Instituto Mexicano del Seguro Social.

- $\quad$ SAAVEDRA DEL RAYO, E. D. (2002). Enfoque de actividades del cineclub universitario en México. Tesis de Licenciatura. México: Universidad del Valle de México.

- $\quad$ TRANRISEVER, B. (2001). Opera functioning as narrative in films; Apocalypse Now - Godfather, Part III - Philadelphia. Tesis de doctorado. Turquía: Universidad Bilkent.

- $\quad$ TSIVIAN, Y. y G. Civjans. (2005). CineMetrics. Movie Measurement and Study Tool Database. Universidad de Chicago. Recuperado de: www.cinemetrics.lv.

- VANOYE, F. y A. Goliot-Lété. (2008). Principios del análisis cinematográfico, Madrid: Adaba.

- ZAVAlA, L. (2010a). Teoría y práctica del análisis cinematográfico. La seducción luminosa, México: Trillas. 
Rocío González de Arce Arzave El Padrino III a modo de Estudio de Caso Revista Xihmai XI (21), 9-28, Enero - junio 2016 (2010b). El análisis cinematográfico y su diversidad metodológica. Casa del Tiempo, 30(3), 65-69.

(2010c). Teoría y práctica del análisis cinematográfico: la seducción luminosa, México: Trillas.

(2012). Tradiciones metodológicas en el análisis cinematográfico. La Colmena 74:9-16.

(2014a). Narratología y lenguaje audiovisual, Argentina: Universidad Nacional de Cuyo Mendoza.

(2014b). Semiótica preliminar. Ensayos y conjeturas, Toluca: FOEM.

Xihmai 28 